\title{
AS GEOGRAFIAS DO ACASO CARTOGRAFADAS EM OUTRAS FRONTEIRAS, DE ANA MAFALDA LEITE
}

\author{
Gustavo Henrique Rückert ${ }^{1}$
}

Pensar o trânsito contemporâneo entre os países que compõem a Comunidade Lusófona é pensar o deslocamento entre as fronteiras erigidas no contexto colonial e que buscaram fixar identidades a partir das relações no âmbito da colonização. É o que faz Ana Mafalda Leite em Outras fronteiras: fragmentos de narrativas. Tendo nascido em Portugal, a autora cresceu e iniciou seus estudos em Moçambique, de onde retornou para atualmente ocupar o posto de docente de Literaturas Africanas na Universidade de Lisboa. Apesar de ser mais reconhecida pelo público brasileiro em seu trabalho como pesquisadora e ensaísta ${ }^{2}$, Ana Mafalda apresenta uma trajetória de mais de trinta anos de poesia ${ }^{3}$. Outras fronteiras, publicada em 2017, é sua nona coletânea de poemas. É, porém, sua primeira obra poética publicada no Brasil.

O livro divide-se em quatro partes. A primeira, intitulada "como se a manhã do tempo despertasse", aborda as fronteiras do próprio sujeito lírico, enunciado em sua condição de deslocamento: "Saberei porventura os lugares de onde fala esta voz? Os enigmáticos espelhos de onde se olha?" (LEITE, 2017: 10). Já a segunda, "poemas de Moatize", constrói-se a partir das recordações da infância em Moçambique: "abriram-se os portais e aqueles com quem sempre estive vão e vêm passam / atravessam a fronteira" (Ibid.: 22). A terceira parte, homônima ao livro, aborda a perspectiva da escrita dos viajantes acerca das terras de Moçambique, unindo suas vozes à do sujeito lírico: "os caminhos são sempre outros, bocas línguas pombeiros sertanejos informantes / desaparecem nos caminhos" (Ibid.: 41). Por fim, a última parte, "o índico em Marrakesh", reescreve os deslocamentos tomando como referência o Oceano Índico. A partir da perspectiva do hibridismo cultural, assinala-se a diferença por meio dos elementos das mais variadas paisagens entre ocidente e oriente: "devagar fomos chegando pelas ruas e múltiplas portas da cidade cor rosavelho / aromatizada de especiarias de incensos e véus inesperados" (Ibid.: 58).

\footnotetext{
${ }^{1}$ Universidade Federal dos Vales do Jequitinhonha e Mucuri, Brasil.

${ }^{2}$ Destaco aqui as obras A Poética de José Craveirinha (1990), Oralidades \& Escritas nas Literaturas Africanas (1998) e Literaturas Africanas e Formulações Pós-Coloniais (2003).

${ }^{3}$ Destaco aqui as obras Em sombra acesa (1984), Rosas da China (1999) e Livro das encantações (2005).
} 
Em comum às quatro partes está o manifestar de um sujeito lírico em trânsito, como já anunciava a seção que abre a obra. Ao movimentar-se pelas fronteiras do antigo império, relativiza-as. Relativiza-as não simplesmente do ponto de vista físico, mas identitário - dialogando assim com as fronteiras culturais erigidas no processo colonial. De acordo com Doreen Massey (2008), o espaço não pode ser considerado como algo estático tal qual o limitaram os estudos que o definiram em oposição funcional ao tempo. Para a geógrafa, o espaço está sempre em construção e caracteriza-se pela multiplicidade, uma vez que é produto de inter-relações. Nesse sentido, pensar o espaço é pensar na disputa de narrativas que procuram significá-lo e ressignificá-lo.

Em Outras fronteiras, o sujeito lírico em trânsito insere sua voz em meio a essas disputas acerca dos espaços envolvendo o trajeto entre África e Europa. Dessa forma, cartografa o espaço outrora caracterizado pelo colonialismo português na contracorrente. Tomando como ponto inicial da construção de sentidos Moçambique - o local da infância assinalado pela referência metonímica a Moatize -, o deslocamento assume um sentido inverso à literatura de viagem colonial: da "colônia" aos "outros mundos". É no solo africano que a terra acaba e o mar começa. O sujeito detentor da voz, aquele que nomina o espaço e a alteridade, parte de África.

Essa poética de um deslocamento que parte de África, transgredindo as fronteiras do mundo colonial, é assinalada textualmente das mais variadas formas. Elenco, nesse sentido, as seguintes imagens do transitar, presentes no decorrer dos poemas: roda de insetos; feitiço de escrita; azul ultramarino; bola de tênis; rio Moatize; Máscara Kapoli; Máscara Kampini; Máscara Dzwirombo; geometrias do acaso; interstícios. Igualmente, elenco as fronteiras transgredidas por essas imagens: dia e noite; poeta e poesia; vida e morte; criadores e criaturas; homens e animais; chuva e queimada; água e terra; ocidente e oriente; poesia e cartografia; voz do eu e voz do outro; um lado e outro da quadra de tênis; as cores, os aromas e as texturas. As imagens assinaladas propõem a transgressão das mais diversas linhas divisórias que a compreensão humana impôs ao mundo para controlá-lo, tornando-se o próprio poema algo que escapa aos contornos e não pode ser apreendido em suas fronteiras. Em "Fronteiras, de que lado pergunto-me", o sujeito lírico questiona: 
onde terá começado a fronteira do dia com a noite? a fronteira da água com a terra? a do azul com o lilás? porque tão dividido

o mundo em dois? no tratado de tordesilhas levou-se a ibéria ao novo mundo e mais tarde sentados em berlim muitos outros desenharam os mapas a compasso e esquadro

um continente não interiormente navegado diziam kurtz apontando o dedo ao acaso em caligrafias de cor ou a tinta da china um coração das trevas mapa cor de rosa a estilete gravado

nas mãos os mistérios arcos de décadas em bissectriz dançando a caneta em forma de bisel (LEITE, 2017: 34)

Se por um lado a estrofação é uma forma de dividir os versos, levantando fronteiras em um texto poético, por outro busca-se uma forma fluida por meio dos enjambements, do fluxo expressivo, dos versos longos, das iniciais minúsculas, da profusão de diferentes vozes pelas referências intertextuais. É assim que essas primeiras estrofes transitam das fronteiras astrológicas (dia e noite), substanciais (água e terra) e cromáticas (azul e lilás) para pensar as fronteiras geopolíticas do passado colonial. É assim que o imaginário orientalita (Cf. Said, 2007) é evocado como forma de definir o espaço alheio, seja por meio dos textos ficcionais, como Coração das trevas (1889), de Joseph Konrad, seja por meio de acordos políticos, como o Tratado de Tordesilhas (1494) ou a Conferência de Berlim (1884-5), ou ainda por meio das pretensões lusitanas sobre o domínio de territórios africanos no Mapa Cor-de-Rosa (1890).

E se a cultura orientalista do colonialismo, com caneta, estilete, bisel, bissectriz segmentou, definiu, catalogou e classificou territórios, culturas, línguas e povos, o sujeito-lírico utiliza o espaço de seu poema para escrevê-lo a partir do insterstício: o espaço intervalar entre literatura e realidade, entre ficção e política, entre poesia e narrativa, entre versos e estrofes, entre o espaço colonial imposto e o espaço assumido pelos sujeitos que herdam a sociedade colonial.

Ao evocar essa condição intersticial para ressaltar as fronteiras que não possui, Ana Mafalda Leite insere-se em uma vertente da poesia moçambicana que pode ser destacada a partir de figuras como Rui Knopfli, Luís Carlos Patraquim e Eduardo White. Se nomes como José Craveirinha e Noémia de Sousa foram responsáveis por uma poesia de combate, que prezava pela territorialidade em uma poética fundada no espaço moçambicano e africano, tendo o corpo negro como materialidade da resistência 
ao colonialismo, os poetas ressaltados destacaram-se pela ambivalência entre os elementos culturais portugueses e moçambicanos.

Dessa forma, em oposição à relação telúrica que fixa o sujeito identitariamente à terra, pode-se pensar a partir de Knopfli, mas também em Patraquim e White, uma tradição poética que preza pelos fluxos, pelos deslocamentos, pela diferença ${ }^{4}$. Não ao acaso, em todos esses poetas o Índico e o Oriente são símbolos frequentemente utilizados para marcar o lugar de uma poesia que preza pela modernidade, pela sinestesia e pelas referências metapoéticas, evocando diferentes tradições culturais e literárias, também rasurando as fronteiras pelo transitar.

A poesia de Ana Mafalda Leite se insere nessa poética do deslocamento simbolizada pelas correntes do Índico em oposição à fixidez da terra, alternando referências à poesia e à cultura moçambicana, mas também a uma modernidade literária para além do nacional. Em "Poemas do Nyau, a grande dança", que compõe Outras fronteiras, a máscara Dzwirombo afirma: "somos os misturados descoincidentes zoomórficos / criaturas e criadores" (LEITE, 2017: 30). Assim como a máscara, a poesia reivindica o reverso da identidade, reivindica ser misturada e descoincidente, ser moçambicana e portuguesa, ser oriental e ocidental, buscar a modernidade da poética de um Patraquim, mas também trazer à tona a tradição da voz de um Craveirinha.

No posfácio da edição brasileira de Outras fronteiras, Carmen Tindó Secco (2017: 76) assinala: "Entre Ocidente e Oriente, Moçambique só é possível pelo cruzamento de 'acasos conjurados', voz do passado rente ao Índico e às diversas etnias africanas que habitam a terra moçambicana". É justamente esse cruzamento de acasos conjurados que permite que os poemas rasurem as fronteiras erigidas na colonização, sejam elas espaciais, identitárias ou poéticas. Se o espaço é de fato o confronto de narrativas que o significam, como defende Massey (2008), Ana Mafalda expande em seus versos o nosso mundo, assinalando a presença das fronteiras coloniais para rasurálas, trazendo à tona os discursos do passado para que compreendamos o presente.

No poema "Os itinerários sem mapas", o sujeito lírico destaca seu desejo de cartografar: "registo tudo aquilo que me permita vir a construir um mapa nestas páginas

\footnotetext{
${ }^{4}$ Em seu trabalho como pesquisadora, Ana Mafalda Leite (2012) assinala a importância dos elementos, como a terra e o fogo, a água e o ar, na escrita da nação na literatura moçambicana. A partir de nomes como Patraquim, White, de Lemos e Mia Couto, chama atenção para os dois últimos elementos.
} 
que mal consigo ver" (LEITE, 2017: 48). No entanto, ao final do texto, destaca a impossibilidade dessa cartografia: "Intuo que não chegarei ao fim desta jornada / os mapas irão perder-se comigo algures por estes descaminhos / Procuro em vão desenhar os itinerários de ouro entre oriente e ocidente" (Ibid: 49). E se essa perspectiva intersticial não cabe nos mapas, só é possível caber na ausência de fronteiras da poesia não de qualquer poesia, mas de uma poesia que se anuncia pelo deslocamento, que se vincula aos fluxos culturais de uma poética do Índico.

E assim, para além das fronteiras que não temos, mas que nos foram impostas desde cinco séculos, buscamos no presente ouvir a poética voz que se anuncia "do outro lado do tempo, num outro mar e num outro continente" (Ibid.: 73), como destacado em "Caminhos no deserto", poema que encerra Outras fronteiras mas não se impõe como fronteira, abrindo-nos a possibilidade de navegar.

\section{Referências}

LEITE, Ana Mafalda. Outras fronteiras: fragmentos de narrativas. São Paulo: Kapulana, 2017.

Poéticas do imaginário elemental na poesia moçambicana - entre mar... e céu. In.: _. Oralidades \& escritas pós-coloniais: estudos sobre literaturas africanas. Rio de Janeiro: EdUERJ, 2012. p. 297-305.

MASSEY, Doreen. Pelo espaço: uma nova política da espacialidade. Trad. Hilda Maciel; Rogério Haesbaert. Rio de Janeiro: Bertrand Brasil, 2008.

SAID, Edward. Orientalismo: o Oriente como invenção do Ocidente. Trad. Rosaura Eichenberg. São Paulo: Companhia das Letras, 2007.

SECCO, Carmen Lucia Tindó. Outras fronteiras: o brilho dos pirilampos e os fragmentos da memória. In.: LEITE, Ana Mafalda. Outras fronteiras: fragmentos de narrativas. São Paulo: Kapulana, 2017. p. 74-76.

Recebido 01/07/2019

Aprovado 24/07/2019 